Vantage: Journal of Thematic Analysis

ISSN: 2582-7391

A Multidisciplinary Publication of Centre for Research,

Maitreyi College, University of Delhi

October 2021, Volume 2, Issue 2

Original Research Article

\title{
Farmers' Lives in the Wake of Sustainable Development
}

\author{
Priti Mendiratta Arora ${ }^{1 *}$, Aruna Grover ${ }^{2}$, Vanshika Gulia ${ }^{1}$, Laxmi Kumari Mahato ${ }^{1}$, \\ Pooja $^{2}$, Ritika Choudhary ${ }^{2}$ \\ ${ }^{1}$ Department of Economics, Maitreyi College, University of Delhi \\ ${ }^{2}$ Department of Sociology, Maitreyi College, University of Delhi \\ *Correspondence: parora@maitreyi.du.ac.in
}

\begin{abstract}
The objective of this research is to study the socio-economic challenges faced by farmers in the wake of sustainable agriculture in India. This paper identifies issues related to sustainable agriculture that contribute significantly to the lives of rural populations and examines the role of Non-Governmental Organizations (NGOs) in addressing them. The study also seeks to focus on the replicability of sustainable agricultural practices. The analysis is conducted through online surveys and telephonic interviews with farmers and members of NGOs working in the area of sustainable agriculture. It has been found that the practice of sustainable agriculture is growing. However, despite this positive assessment, sustainable agricultural practices have encountered numerous challenges like the inappropriate use of chemical fertilizers and pesticides, hesitation to opt for new practices, shortage of resources, gender discrimination, landholding being too small to make sustainable farming practices economically viable, and many more. The involvement of NGOs and other self-help groups in the lives of farmers, in order to pursue sustainable agriculture, has made a positive impact. Although developments are taking place, the rate is quite low. Therefore, we may conclude that change for the better is coming albeit gradually and more active steps towards the process need to be taken.
\end{abstract}

Keywords: Sustainable agriculture, Development, Economy, Equality, Resources 


\section{INTRODUCTION}

Sustainable agriculture is composed of agricultural practices that are economically viable, socially supported, and ecologically sound. It aims to preserve society's food and textile needs without hampering the ability of future generations to meet their own needs. It is considered beneficial in the long run from a social, ecological, and economical point of view. Sustainable agricultural practices not only replenish the depleted soil, while reducing the use of non-renewable resources, but also improves water conservation and storage measures. Most importantly, sustainable agriculture is regarded to be a medium in reaching global food security without enlarging land usage and minimizing environmental impacts (United Nations Report, 2007).

India's agriculture budget doubled over five years to ₹57,600 crores in 2018-19 (Union Budget of India, 2018-19). In the 2020-21 union budget, the Ministry of Agriculture and Farmer Welfare has been allocated ₹1,31,531 crores. Despite this increment in the budget allotted to the agriculture sector, a large section of farmers in our country is impelled to practice agriculture using manual techniques and seasonal irrigation links. Despite farmers getting free electricity and water supply, subsidies in loans, equipment, and a tax-free income, farmers' distress is the sad reality of our farmers. Recent decades have witnessed "an epidemic of farmer suicides."

The average Indian farmer is quite poor. To exemplify, cotton was referred to as white gold once, a farmer could sell 1 quintal of cotton and buy approximately 15 grams of gold. But now he probably has to sell 15 quintals of cotton for just 1 gram of gold or even less. It shows how much the universe of farmers has collapsed. And with that, their status and dignity collapsed. People no more respect those who make their food and ours. This has been the condition of farmers for the last few decades. The degrading dignity and rising debts of the farmers are major constraints to sustainability.

One of the most debated issues in the Indian farming industry today is the role of corporations or finance - tycoons in agriculture. Corporatization of agriculture consists of commercialization of the agricultural sector by farming on lands owned or influenced by large corporations. The presence of these corporations increases the market value of the produce and ensures profitability for small and marginal farmers. However, in the 
long run, farmers may end up being in loss due to the high demand for a specific produce and the delicate nature of farming itself. Through corporatization, MNCs gain access to the production and distribution of agriculture and its produce and thus stand to gain monopoly over farmers. They can pressurize farmers to sell their produce at low costs and buy seeds, fertilizers etc. from the MNCs at high costs. This monopoly or oligopoly of agriculture ends up making higher profits for corporations resulting in farmers being poorer day by day. It raises the input cost of farming and retains the profits of the output, leaving farmers with next to nothing. This situation is even worse in developing countries like India, which are largely agriculture-based economies. Sometimes farmers face huge losses and get stuck in a debt trap due to crop failure and many of them even commit suicide, which is a matter of grave importance. This indicates the need for a serious review of our agriculture policies. If our farmers' lives are in deep distress, despite freebies and subsidies, as a nation, we should be deeply concerned, and take suitable action. The government claims to have done just that through the new agricultural policies, but the farmers, through their agitation, have rejected these policies as anti-farmers, and pro-capitalists.

In such conditions, implementing the idea of sustainable agriculture at the grassroots level is difficult as it needs resources and inputs from the farmers themselves, government, NGOs, technology, society, economy, agricultural sciences, environmental sciences, corporate sector, and more. Sustainable techniques like poly-farming, advanced irrigation technologies, natural pest control, natural farming, etc. are still out of reach for many farmers. Apart from the above challenges, natural disasters like frequent floods, landslides, droughts, famines, forest fires are barriers to sustainable agriculture. As a result, the farmers are compelled to use untested cheap pesticides and insecticides, low-quality seeds, unclean water, and chemical fertilizers which will eventually lead to unsustainable farming and deteriorating soil and environment.

Sustainability as a goal of agricultural research and development is a relatively recent concept. National and international research organizations have responded to the increasing importance of sustainability in agricultural development in recent years. Different Non-governmental organizations (NGOs) in India play an important role in the lives of farmers and peasants in many ways. To understand the role of NGOs in the 
lives of farmers engaged in sustainable farming in India, it is important to note that violent conflicts, including civil and military, have negatively affected agriculture in most parts of the country. There is poor agricultural research capacity resulting from market inefficiencies and the collapse of extension services to the public, largely affecting access and use of farm inputs, thus reducing agricultural production. NGOs for agricultural development seek to increase agricultural productivity by nurturing farmers and organizing them into groups to enhance their profitability- striving for sustainable agriculture and rural livelihood. Various NGOs have made continuous efforts to empower the marginalized and deprived members of the rural community with special emphasis on women and children, enabling them through various programs and activities, ensuring sustainable livelihood, distribution of natural resources without discrimination.

On reviewing some of the work done by NGOs over the past three decades in India, we find that they have contributed greatly to nation building. NGOs have played an important role in livelihood enhancement, environment conservation, promoting the use of natural resources (rather than relying on chemicals), working on skill development of farmers, empowering women, educating children, and creating awareness on different government schemes to help small farmers. Some of the major activities taken up by the NGOs are watershed management program, vermin-composting, microfinances, agricultural cooperatives, extension services etc. NGOs, as the operational arm of the civil society therefore have an important role in the development processes in India. Several NGOs of India have the support of the World Bank, NABARD, other multilateral agencies, foreign aid agencies and Government at the central, state and district levels. Many national and international NGOs have contributed towards building a positive environment for sustainable agriculture, but this is only the beginning, and the long and arduous journey has just begun.

This paper identifies and analyses the viability of sustainable agriculture in India, the challenges that are associated with its implementation and the way it is affecting farmers' lives through identification of issues related to the implementation of sustainable agriculture and the problems associated with the agricultural sector - for example, gender discrimination, social, economic, and power inequalities, underemployment, and 
unemployment. It also seeks to examine the role of NGOs in addressing various challenges faced by farmers while adopting sustainable agricultural practices.

The remaining part of the paper is divided into five sections. Section 2 deals with the methodology of the paper, section 3 presents a discussion about NGOs working in sustainable agriculture while section 4 represents the farmers' perspective, section 5 discusses the APMC act and section 6 focuses on the conclusions and recommendations.

\section{METHODOLOGY}

The paper follows a qualitative research approach. Due to constraints imposed by the Covid-19 pandemic, most of the fieldwork was conducted through online interviews and surveys with the senior employees of various NGOs, Self Help Groups (SHGs), and organizations and with some of the beneficiaries of these organizations that are working towards the development of sustainable agriculture. Structured interviews were used to know about their efforts, issues, and expectations at the grassroots level. We asked them questions varying from general information about their organization, their journey, the challenges, achievements, and their views regarding the development of sustainable agriculture.

We conducted an online survey of the NGOs working on sustainable agriculture and tried to contact them telephonically for interviews. Unfortunately, very few organizations responded to our emails and telephone calls. The offices of most of the NGOs were shut down due to Covid, and communication was very difficult despite repeated efforts. This remains a limitation of this research project. This report provides case studies of three NGOs namely Ramkrishna Jaidayal Dalmia Seva Sansthan (RJDSS); , Preservation and Proliferation of Rural Resources and Nature (PRAN); and Centre For Dignity. This selection is representative of the sample that has been surveyed.

Apart from the telephonic interviews with the senior employees of the NGOs, we also consulted the farmers at the ground level to understand their challenges in their own words. The fieldwork included interviews with farmers from the states of West Bengal, Bihar, Haryana, and Orissa. They were asked questions about the techniques they are using and the reasons for adopting those techniques. We also asked them about the 
support they seek from the government. Taking the current situation of Covid into consideration, proper care of hygiene was taken and covid protocols were followed. It was ensured that the interviewer and the interviewee were vaccinated before the interview.

Special care was taken to ensure that the research follows all possible ethical norms such as filling out a consent form before the interview, seeking permission to record the interviews, disclosure or non-disclosure of names, and quoting them in this paper ensuring their privacy and also maintaining the authenticity of the research.

We also relied on secondary sources like websites of NGOs, books, journals, articles, government reports, and NGO reports, etc. A sample of over 100 NGOs, privatelyowned organizations, Self Help Groups that are working towards the development of sustainable agriculture in India was selected for the same. Going through the websites of all the NGOs working in sustainable agriculture helped in understanding the nature and scope of their work. Based on this survey, a spreadsheet was prepared to analyze the details of their work - area of operation, the number of villages under them and farmers they covered, their success rate, and other issues. After receiving all the responses through the above methods, we identified, analyzed, and marked all the major socio-economic issues as mentioned by them.

\section{FINDINGS FROM NGOs}

\subsection{Ramkrishna Jaidayal Dalmia Seva Sansthan}

"Ramkrishna Jaidayal Dalmia Seva Sansthan" (RJDSS) was established in 2004. RJDSS is currently operating with 55,000 people across 88 villages at Chirawa block of Jhunjhunu District of the famous Shekhawati Region in Rajasthan. In the last 14 years, the areas of their operations are - drinking water, agriculture and livestock, sustainable use of natural resources, women's empowerment, youth development, and addressing various other social issues. During an interview, a manager of the Sansthan informed us that water conservation and promotion of total sanitation in the villages has been successfully achieved in fifteen villages and that was acclaimed nationally by several awards (at different levels by different organizations). 
The basic approach of the Trust, according to our informant, is to empower rural communities, revive their traditions of water conservation and rainwater harvesting by rehabilitating the older structures and also using modern scientific knowledge and technology to provide drinking water security in all climatic conditions.

They have created awareness among villagers on various issues related to water, the environment, and agriculture. At the organization level, they found that the community has been very supportive in their journey of one and a half-decade of rural development.

\subsection{PRAN: Preservation and Proliferation of Rural Resources and Nature}

PRAN is based in Bodh Gaya, Bihar. Its operations are spread across the state. The organization got registered in November 2012. They were promoting SRI and later the government spread it in the whole state of Bihar. Our informant from this organization told us that the farmers were invited to Gujarat, by the erstwhile chief minister, Mr. Narendra Modi, in 2013and Rupees 50,000 were awarded to them as a token of appreciation for their contribution in the field. They also got awarded in 2014 at the national level for their work. They work on issues of water harvesting, climate-resilient agriculture, helping in the education of girl children, providing jobs, training, certificate courses, promoting food collection centers in villages, etc. They also train local blacksmiths to make innovative agricultural machines. They motivate farmers for organic farming and claim that they get more produce than those who use chemical fertilizers in the field. They also teach organic compost making using waste materials. They also compose songs to be sung in rural areas for awareness. In 2018 they were declared one of 22 outstanding social workers of India. In 2020 they got the best NGO award. They are in direct contact with 2,09,000+ farmers and around 30,00,000 were benefitted. Students from all over the country come for certified courses and get placement and job opportunities. They have a connection with organizations from 50 different countries and also conduct lectures in foreign universities. They have also been awarded for innovative machines.

\subsection{Centre for dignity}

As told by our informant, the Centre for Dignity began its sustainable agriculture practices in October 2016 in Orissa. From the beginning, the primary focus of the 
organization was on irrigation and the availability of drinking water facilities. Over a period of time, with the support of the government, various structures for sustainable agriculture were built including canals, check dams, wells, etc. Moreover, women farmers are also encouraged in their organization. Female farmers are engaged in the cultivation of crucial beetroot seeds. Currently, five clusters of farmers are engaged in second crop cultivation wherein each cluster consists of 50 farmers with one acre of land provided to every farmer. Turmeric, little millet, and ragi crops are other such crops grown by their farmers. Their agricultural work is based on the concept of sustainability. They work on providing quality seeds and micronutrients so that soil fertility can be retained, soil erosion can be checked, and production can be increased for a longer period. Apart from this, they also focus on renewable energy like providing solar and wind energy access to the farmers. It's been informed that in 20 years, they have covered 403 areas in various states.

\subsection{Findings from the perspective of NGOs and self-help groups: Achievements and challenges}

We have covered more than 100 NGOs from different states of India, where we asked them about their journey towards the implementation of sustainable agriculture, their challenges, strategies, and achievements. We observed that the main focus of these organizations lies in organic farming, water management resources, women empowerment in rural fields, rainwater harvesting, and skill enhancement of farmers so that they could practice sustainable agriculture.

PRAN, an NGO in Bihar, stated that "The farmers in this area are more povertystricken than in other occupations. Their lives are quite difficult." which became one of the primary reasons behind their operation. Also, as in some areas the primary source of income was farming which was rapidly being degraded by the overuse of artificial fertilizers and other inorganic methods of farming, these organizations took an initiative to stop this approach and encouraged farmers to use organic farming techniques. 
Mr Paliwal, the senior Manager of Ramkrishna Jaidayal Dalmia Seva Sansthan informed us that "Chirawa Tehsil being situated on the edge of the Thar Desert faces many problems, so that a lot of work that can be done for the development of their native place." While talking to the NGO workers we got to know that the harsh climatic conditions, lack of water, deforestation, poverty, lack of employment opportunities, are the major problems of farmers of the area.

We noticed that while their areas of operation were different, the focus and the targets were the same for each of them. Being in different states their areas of achievements varied but they faced similar challenges.

Figure 1 below shows the percentage of area per state under organic production. According to the website of Participatory Guarantee System for India (PGS India), which works under Ministry of Agriculture and Farmers Welfare, Madhya Pradesh (28\%) has the largest organic certified area followed by Maharashtra (12\%), Uttarakhand (12\%), Uttar Pradesh (09\%) and Karnataka (09\%). In 2017-18 the production of organic products was recorded around 1.70 million tones, which includes edible products and organic cotton fiber.

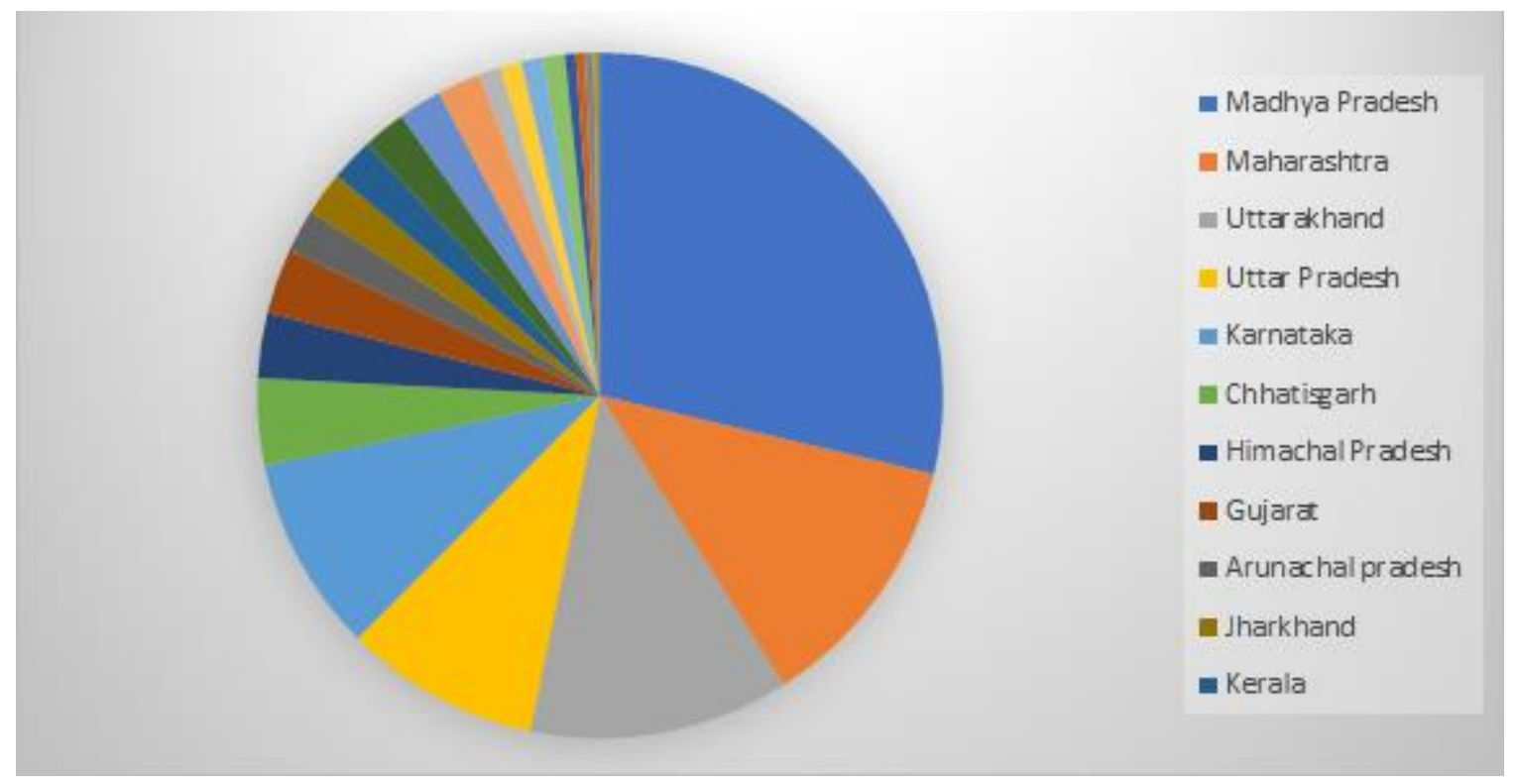

Data source: Roy \& Kumar (2019)

Figure 1: The percentage of area under organic production state-wise distribution 
Post the green revolutions of the 1960s, there has been a shift towards modern techniques, to meet the demands of our growing population. Though modern farming yields greater production, and farmers lives have become prosperous in some regions, it also has many limitations and disadvantages. The degradation of natural resources due to the overuse of chemical fertilizers, insecticides, and pesticides has called for a shift towards organic and sustainable farming. Furthermore, the increase in health problems related to increased chemicals intake by humans - like the rising cases of cancer in many areas - has also given impetus to this movement.

India has 30 percent of the total organic produce in the world, but only 2.59 percent of the total organic cultivation area, as per the 2018 report of World of Organic Agriculture. Sustainable agriculture needs the efficient use of soil, water, livestock, climate, etc. In India, agriculture faces numerous challenges which we came across during our research project. Some of them include:

Low priority in funding by the government: Even though a large amount from the annual budget is devoted towards the agricultural sector, the farmers still face a major problem of insufficient funds. Due to less capital, rural farmers are forced to work with traditional non-sustainable means of agriculture which not only harm the environment but also give them less profit.

Gender inequality is another major issue that was observed. Women contribute $33 \%$ of the agricultural labor force and $48 \%$ of the self-employed farmers, but their work remains unrecognized. Apart from working on fields women also contribute in farms, cattle management, and other household activities, but a large number of women remain "invisible contributors" (Mohan, 2020). Women are constantly working on their family farms, but they are not recognized as "farmers", nor do they get any remuneration for their work. When working on another's farm, they usually get paid less for the same or similar work. They are also involved in agri-related work in the family - like - animal husbandry and poultry farming, food processing, etc., but, here too, they get neither any monetary remuneration nor any gains in kind, or any social benefits. Their lives are generally governed by traditional patriarchal norms. 


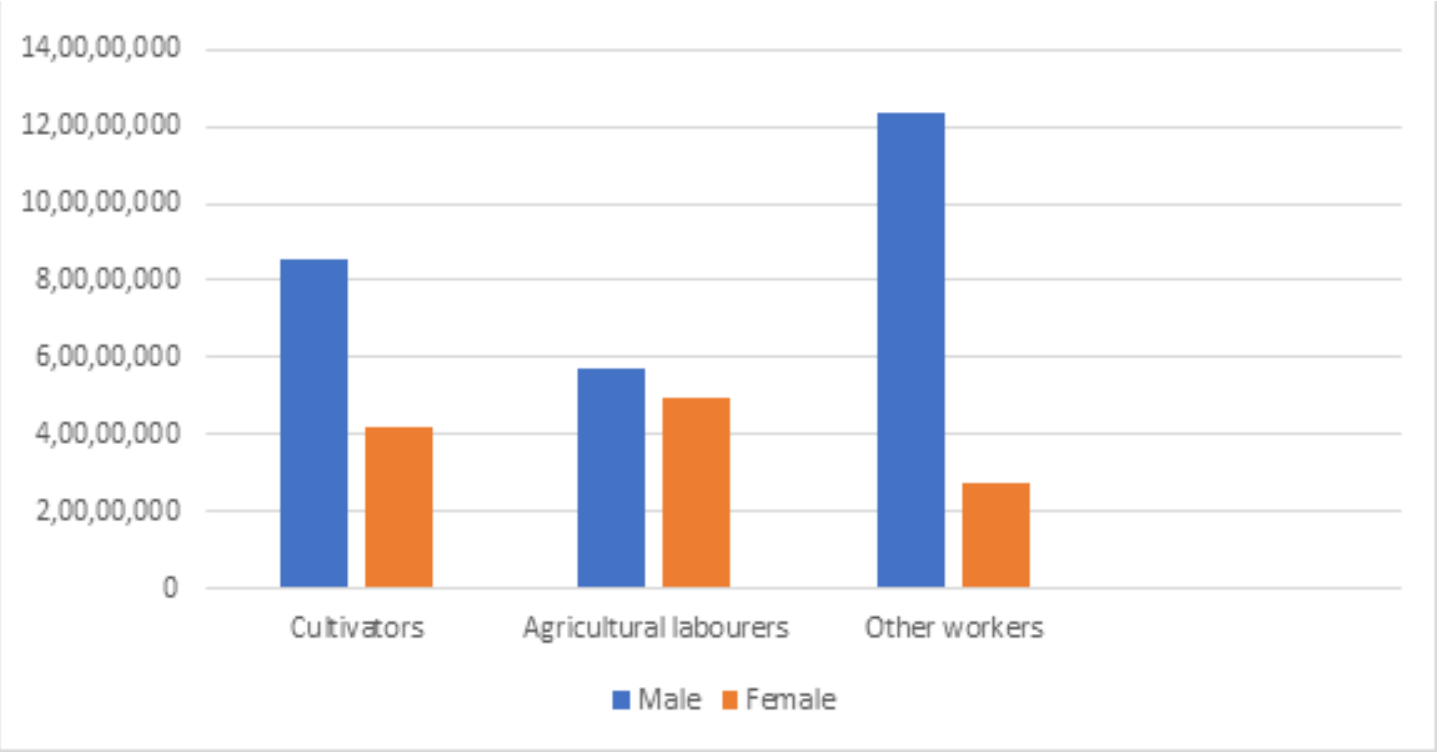

Data source: Office of the Registrar General and Census Commissioner, Ministry of Home Affairs, Government of India (2011)

Figure 2: The male-female distribution of cultivators, agricultural laborers, and other workers in 2011

Figure 2 shows the Indian male-female distribution of cultivators, agricultural laborers, and other workers in the year 2011. According to the Census 2011, the number of female cultivators was less than the number of male cultivators with females being around 41 million $(41,896,353)$ and males being around 85 million $(85,416,498)$. In the same year, the ratio of agricultural laborers is not very different from that of the cultivators' with females being around 49 million $(49,446,230)$ and males being around 57 million $(57,329,100)$. However, the agricultural laborers do not have a sharp difference between their male-female ratio as opposed to other workers. There is a pronounced distinction in the male-female ratio which indicates female participation is significantly less than male participation particularly in the segment of cultivators.

Use of chemical fertilizers: Farmers use fertilizers to increase crop production which has added nutrients to the soil but as a consequence, it has negatively impacted the soil quality, decreased fertility, polluted air, and water, and released greenhouse gases. Crops grown in fertilizer-rich fields contain hazardous chemicals which make their way into our daily meals causing serious health issues. 
Monopoly of middlemen: The presence of various layers of middlemen has been the bane of the Indian farmer since centuries. A middleman is someone who buys goods from the farmers and sells them in the market. The interference of too many middlemen results in the exploitation of both farmers and consumers. They try to gain maximum profit and for this purpose offer lower prices to farmers and charge higher from the consumer.

There are also other challenges like interventions by the government and communities, lack of irrigation facilities, dependence on rainfall, low and contaminated groundwater, the small size of landholding, unpredictable weather conditions and climate change, lack of knowledge about latest technologies introduced in agriculture like latest seeds or equipment.

It is also observed that farmers are often conservative and reluctant to opt for new technologies and improved agriculture practices due to generation-old farming practices i.e., excessive use of groundwater for more production. Government schemes sometimes create challenges like permission for bore-well for farming. This kind of intervention puts the organizations in the back seat on creating awareness. Failing or stagnating growth of factor productivity, rising input cost, fall in profits, the emergence of climate risks, growing regional disparities, volatile prices, unfavorable trade are also some of the factors which adversely affect sustainable agriculture.

Apart from these challenges, it is also observed that there are a lot of basic issues that become a hurdle in the path of implementing sustainable agriculture at a large scale. Amid these challenges, these rural heroes have achieved as much as they could.

During an interview, Mr. Paliwal mentioned that they have built 3740 rainwater harvesting tanks which is benefitting more than 55,000 people by storing 58.95 crore liter water. They have constructed 98 recharge wells, 5 ponds, and 3404 soak pits and have recharged more than 201 crore liter water through these groundwater recharge structures. With the use of sustainable and organic techniques, they have managed to increase farmers' incomes up to $23 \%$ to $36 \%$ and production has increased up to $22 \%$ to $50 \%$." 
A senior manager at PRAN informed us that they are in direct contact with more than two lakh farmers and have directly benefited about 30,00,000 farmers through skill development and the use of organic materials and methods. With their determination and support of the beneficiaries, they have successfully established connections with 50 different countries. Another NGO worker (name not to be disclosed) that we interviewed told us that practicing sustainable agriculture has helped them in reducing the cost of production and generating higher incomes for the farmers.

Dr. Anjali Malik, an independent trainer in sustainable agriculture, shared our concerns about gender constraints in agriculture. She told us that there are a lot of urban and rural women working with her as trainees, and among the 8000 farmers that she has trained to date the percentage of women has increased at an encouraging rate.

With the help of above mentioned discussions, we inferred that the gap, that used to exist and the over-employment that often over shadowed the potential of women in rural fields, has gradually improved and the women are engaged in self-employment and have developed better skills and management. A lot of women Self Help groups have also developed a finance chain through which they help each other in meeting their financial needs. Dr. Anjali also told us about the urban women who own their farmlands and provide organic and natural food to each set of 25 families that are associated with her organization - Natural Farming.

NGOs and self-help groups are usually dependent upon themselves to raise funds, and it becomes difficult for them to manage large or capital intensive projects. Many of their schemes and initiatives fail as they lack proper monetary support and that is one of the reasons that sustainable agriculture in India is still not implemented in large areas. But as we talked to these organizations and came to know about their fascinating achievements, we also got the opportunity to know how they managed the financial sector of their field. The majority of financial requirements are being fulfilled by trustees of the organization with their funds and sometimes by other individual donors and Departments of Central Government (Science and Technology). United Nations, Unicef, donations from private organizations, and other states also provide funds to extend the work in their area. 
Most of the NGOs reported that they have received very positive responses from farmers because of the benefits they are getting - organizational support and all the benefits of sustainable agriculture. Many farmers have now started to adopt new technologies like the improved variety of seeds, organic farming methods promoted by these NGOs, and self-help groups. Farmers have also adopted a new concept of farming i.e., integrated farming systems (IFS) like horticulture, animal husbandry, and crop production. We could also find various cooperative groups being formed by women to train other women to actively participate in the process.

In addition to their efforts regarding sustainable agriculture, the NGOs and self-help groups express their expectations from the government. While current government schemes are helpful for farmers, their implementation is not always very effective. This is due to their improper or untimely implementation. Government schemes are not readily available to the farmers due to the limited availability of resources.

\section{THE PERSPECTIVE OF THE FARMERS: CHALLENGES AND ACHIEVEMENTS}

In our field visits to the farmers of West Bengal, Bihar, Haryana, and Orissa, we were able to conduct face-to-face interviews with seven farmers actively participating and practicing sustainable ways of agriculture. We talked to them about their lives, experience in this field, views on sustainable agriculture, challenges that they have faced while practicing the same, and their vision for the future of sustainable agriculture.

The farmers from the states of West Bengal and Bihar told us that they have been practicing sustainable agriculture for two years and under the guidance of NGOs. Upendranath Mahto, an independent farmer from Bayedhet, West Bengal told us that about $80 \%$ of their village is now engaged in practicing sustainable agriculture and they are trying to connect with other villages also. They are getting good monetary benefits and since the process is simple and beneficial, getting rid of chemical fertilizers seemed the right choice to them.

Another farmer Gajendranath, of the same village, spoke of "...leaving behind the traditional ways of farming and opting for the new methods. It scared us at first, but 
then, the thought of benefits like good health, high profits and financial security motivated us to adopt it." The farmers, thus, when they were able to see the benefits of sustainable farming, were open to it.

Considering the domination of the traditional style of farming still enjoys, adopting a new technology-oriented way has to be difficult for our farmers. While talking to the farmers about the same we found out that there were several motivating reasons to opt for sustainable agriculture such as high income as compared to traditional farming. Having seen the adverse results of the usage of chemical fertilizers, the farmers believed farming is something that should remain organic. They realized how our resources are scarce and require attention and action to be sustained for future generations.

As we talked about the achievements at the farmers' level we found that all of them were pretty enthusiastic and happy with the results. They have been into organic farming for more than a year now and are extremely satisfied with the quality of goods as well as the profits gained from them. Sustainable agriculture practices are now being adopted by various villages in the rural area with the help of different NGOs and community groups providing them everything that they possibly could. They actively participate in, and organize various campaigns to make other farmers aware of the importance of sustainable agriculture and eventually influence them to bring it into practice. While their lives have not been dramatically transformed by the practices of sustainable agriculture, they realize that they are making a difference - to the lives of their future generations, to the planet.

The main challenges that the farmers faced were - the lack of awareness among people, low funding, middlemen monopoly, and lack of resources. According to them, people respect their traditional way of farming way too much to accept any change and leave behind the traditional techniques. Resources such as land, labor, and water are scarce which makes it difficult to opt for sustainable agriculture. Funding is low, which again makes it difficult to afford the technology to fully adopt a sustainable way of agriculture. The majority of our farmers are poverty-stricken. In such situations, tools and materials used in sustainable agriculture are not affordable for everyone.

Most of the farmers think that sustainable agriculture practices are very reasonable, although a little hard to adopt. According to Mr. Upendra Nath Mahato, "acche prachar 
ke madhyum se hum logo ko jagruk kar sakte hai", meaning with a good marketing technique we can make people aware of how easy and important it is to adopt sustainable agriculture. They also said that the life expectancy of the crops is now longer. As the produce grows organically it tends to preserve itself for a longer period leaving low chances of crops going to waste. That also leads to higher profits than before.

Women contribute more than 70 percent of the labor force in Indian agriculture, yet impact studies focusing on gender outcomes of sustainable agriculture practices are minimal. Most of the farmers believed that increasing awareness among farmers, subsidies to the poor and women farmers, and systematic funding could prove a big hand in avoiding these setbacks.

\section{FARMERS' AND NGO'S PERSPECTIVE ON APMC ACT}

Concerning the recently proposed amendments in Agricultural Produce Market Committee (APMC) Act, 2020, the interviewed NGOs have shared positive views stating that if the implementation is properly carried out, these laws will be a boon for the agricultural society. It is beneficial for small and marginalized farmers as it will provide them with exposure and a wider market to sell their produce at the best available prices. According to them, it will create a competitive market environment and will also prevent wastage of agricultural produce which occurs due to lack of storage facilities.

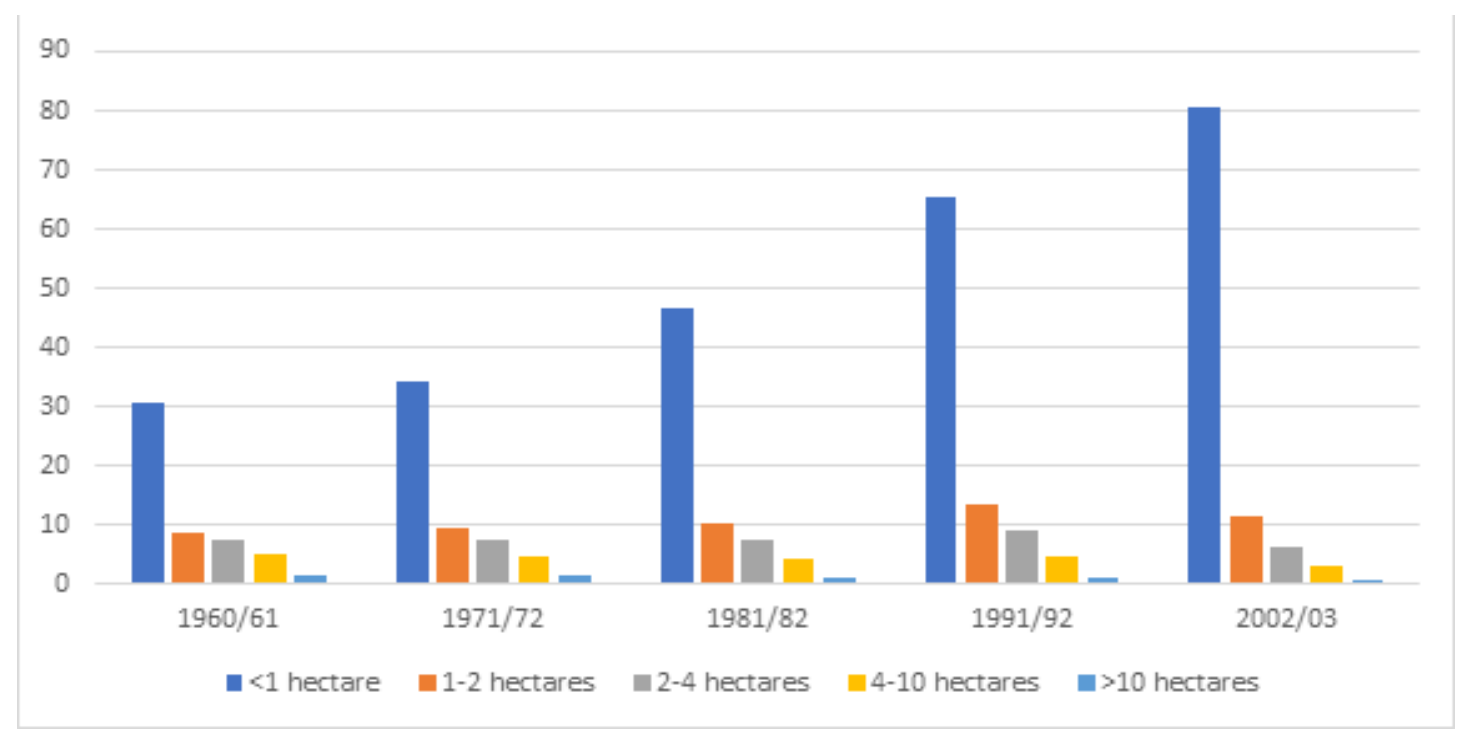

Data source: Cagliarini and Rush, 2011, p. 15-22

Figure 3: The distribution of land for sustainable agriculture in rural areas 
Figure 3 depicts the rural land distribution in India. Over the past 50 years, the percentage of farmers with less than 1-2 hectares of land has been increasing gradually. However, the percentage of farmers over 10 hectares of land holdings is decreasing significantly. Recent data has shown farmers having a farm size of over 10 hectares is just 0.5 percent. The average farm size has dropped to around 1 hectare, which is an inadequate size for a farmer to grow his crops and gain profit. This is a major cause of poverty in the agricultural sector. Smaller land holdings are causing difficulties in agricultural productivity as farmers have less incentive to practice multiple cropping. Due to less productivity and output, farmers are more likely to suffer financially and get trapped in the debt trap. Furthermore, the increasing population has also led to smaller farm sizes. With the division and subdivision of family landholdings, the plot size has become too small to be adequately used for farming.

NGOs believed that since landholding is reducing each year due to urbanization and industrialization, farming on small land is not profitable or sustainable for such farmers. It has high costs and low returns, therefore, corporate farming is preferable for small farmers. In corporate farming, their risks will be reduced drastically, the corporates will take the responsibility and farmers will get an assured return. It will also enable farmers to use modern technologies and various other inputs, thus helping both farmers and consumers while bringing price stability.

The farmer fraternity, on the other hand, fear that the corporations will buy them out, and they will be left without their land, without adequate compensation, and without the skills to take up any other occupation. History has shown that such competition among unequal's usually has very detrimental consequences for marginalized communities. Thus, the poor and women, landless laborers could lose their livelihoods.

\section{FUTURE POSSIBILITIES}

Since sustainable and organic farming is the need of the hour, some of the farmers have begun practicing organic farming in their fields. After the interviews with NGOs, farmers, and the online survey, we realized that the practice of sustainable agriculture is growing. Trends are changing for the better and people are prioritizing the quality of the foods over their prices. However, despite this positive assessment, sustainable 
agricultural practices have encountered numerous challenges like the inappropriate use of chemical fertilizers and pesticides, hesitation to opt for new practices, shortage of resources, gender discrimination, landholding being too small to make sustainable farming practices economically viable, and many more. Since organic methods do not yield high produce, these farmers face an unfair disadvantage in the market and hence sometimes face loss. Moreover, gaining organic farming certification is a little challenging which makes it further difficult for farmers to pursue it.

Accepting a change this big was never easy on those who opted for sustainable farming. With corporates constantly trying their way into the sector and decades long of exploitation, it's been hard. However, the involvement of NGOs and other self-help groups in the lives of farmers in order to pursue sustainable agriculture has impacted in a positive manner by making them realize the importance of their role in today's society. They are educated on the 'what', 'why' and 'how' of sustainable agriculture which made them open to options other than traditional farming.

Our farmers surely see sustainable agriculture to be the future but also realize that it is still a long way to go. They told us that with the speed that we are running now, it will take generations to fully adopt sustainable agriculture as the efforts put in right now are not enough. They also acknowledged that use of chemical fertilizers is so deeply rooted in the agriculture sector, that it will be impossible for us to get rid of them in a short span. It has to be a slow process to gradually erase chemicals from the agriculture industry. They believe that in the next ten years up to $20 \%$ of the farmers in India will be successfully adopting sustainable agriculture.

At an organizational level, NGOs and self-help groups suggested a myriad of initiatives that can be taken for the enhancement of the current agricultural situation. These initiatives include building a common platform for farmers, like the Farmers' Produce Organization (FPO) to help reduce the cost of cultivation by procuring a large number of agricultural inputs at low cost and increase their income by negotiating a mutually beneficial price from the buyer. To raise awareness of the farmers regarding current farming policies, government schemes, and market strategies, a common service center should be built with the availability of adequate resources including magazines, journals, 
newspapers, internet connectivity, and expert guidance. On the field, farmers should adopt an integrated farming approach wherein farming is accompanied by horticulture and animal husbandry. It will ensure that an equilibrium is maintained in the ecosystem. Furthermore, to replenish the soil health depleted by the overuse of chemical fertilizers, insecticides and pesticides, the carbon content in the soil should be increased. It will reinforce nutrient and moisture retention capacity in the soil. Lastly, farmers should be actively engaged in both rural and urban areas so that they get suitable opportunities to sell their organic produce at reasonable rates. This will give farmers exposure to markets and healthy food to consumers. Regular training programs for value addition should be conducted. For that purpose, a common technology demonstration center is needed at least at the Tehsil level. It will make farmers aware of marketing strategies. Apart from this, mini-kits must be provided to farmers. Recently, the government has launched a seed mini-kit program to boost production in the agricultural sector. The timely distribution of these mini-kits will result in better implementation and thus better results. However, for rural and marginal farmers, knowledge of how to use modern techniques and products is just as important as obtaining them. So, to equip each farmer with these facilities, a guide or manual and proper training should also be provided.

To open new doors for the next generation of farmers, the government should invest in creating new technologies and infrastructure for farmers. This will not only ensure food sufficiency in the country but will also develop the agricultural sector resulting in better opportunities for future generations. It is necessary to understand that though monopoly of agriculture is dangerous for society, corporatization is not. MNCs may take advantage of farmers to squeeze out every profit only when they have complete control over the process. The state needs to invest in this sector also, instead of completely relying on the private sector to boost agricultural produce. Along with this, the state needs to launch farmers- favored policies for their welfare and development. That being said, corporatization of agriculture can bring out impressive results if both public and private sectors collaborate in order to safeguard the interests of both farmers and consumers.

Although developments are taking place, the rate is quite low and it would take decades to acquire sustainable practices at a large scale. The farmers also realize that their lives would be positively impacted by natural farming and are enthusiastically opting for new 
methods. The future of agriculture lies in its sustainability. If we can turn to organic farming, optimize usage of natural resources, conserve water, only then can we ensure that our future generations will be healthy and the environment will be safe for all. We acknowledge the fact that this process will take years but considering the current circumstances, strict measures towards the process need to be taken now. Therefore, we may conclude that change for the better is coming, albeit gradually.

\section{ACKNOWLEDGEMENT}

We would like to express our sincere gratitude to the Centre For Research, Maitreyi College for providing us with the golden opportunity to do this wonderful research on "Socio-Economic Issues of Sustainable Agriculture in India". Their guidance helped us in all the time of research and writing of this paper. we would also like to thank $\mathrm{Mr}$ Dalmia (RJDSS), Mr Anil Verma (PRAN), Mr Ajaya(CFD), Ms Anjali Malik (Teacher, Natural Farming) and few others for agreeing to take part in this research project and allowing us to interview them. Their encouragement, insightful information of the field and cooperation throughout this project has enlightened us. Our sincere thanks also go to Mr. Upendra Nath Mahato, Mr. Gajendra Nath Mahato, Mr. Avakash Pradhan, Mr. Neelkamal, Mr. Dara Singh, and Mr. Rajesh Jindhad for providing us their side of the story as farmers and taking the time to talk to us. Their contribution to this paper has been important. We thank our friends Mr Prabhat Kumar and Ms. Tannu Kumari for personally reaching out to farmers of Bihar and Haryana on our behalf for conducting the interview. We are grateful for their help and all the discussion that we have had in the past two months. Their contribution helped us to enhance our paper.

\section{REFERENCES}

Cagliarini A., \& Rush A. (2011, June). Economic development and Agriculture in India. Bulletin, June quarter, pg 15-22.

Food and Agriculture: the future of sustainability. United Nations Report (2007). https://sustainabledevelopment.un.org/content/documents/agriculture and food the future of sustainability_web.pdf

Manthan (2018, August 18). Manthan with P Sainath on Inequality \& Agrarian Distress. [Video]. Youtube. https://youtu.be/CrLQrZOVwXc 
Mohan, V. (2020, Feb 2010). The Women the Unsung Warriors of Indian Agriculture. Dhanuka. https://www.dhanuka.com/blogs/women-the-unsung-warriors-ofindian-agriculture

Roy A., \& Kumar N. (2019, October 10). The government needs to midwife Indian agriculture to an organic revolution. DownToEarth. https://www.downtoearth.org.in/blog/agriculture/the-government-needs-tomidwife-indian-agriculture-to-an-organic-revolution-67177?hcb=1

Union Budget of India (2018-19): Key Highlights of India's Budget. India Brand Equity Foundation. Union Budget of India (2018-19): Key Highlights of India's Budget $\underline{\mathrm{IBEF}}$

How to cite this article: Arora, P. M., Grover, A., Gulia, V., Mahato, L. K., Pooja, \& Choudhary, R. (2021). Farmers' Lives in the Wake of Sustainable Development. Vantage: Journal of Thematic Analysis, 2(2):

DOI: https://doi.org/10.52253/vjta.2021.v02i02.07

(C) The Author(s) 2021.

This work is licensed under a Creative Commons Attribution 4.0 International License which permits its use, distribution and reproduction in any medium, provided the original work is cited. 